\title{
CONVIVENDO COM A SíndROME CONGÊNITA DO VÍRUS ZIKA: MÃES E CRIANÇAS, COTIDIANO E CUIDADO
}

\section{Ana Claudia Camargo ${ }^{1}$, FláVia Lima ${ }^{2}$ e Soraya Fleischer ${ }^{3}$}

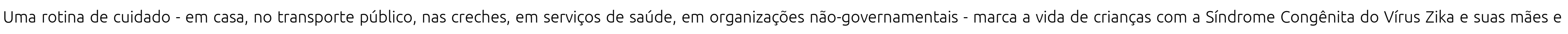
famílias em Pernambuco, epicentro da epidemia do vírus Zika nos idos de 2015

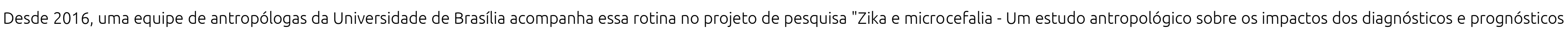

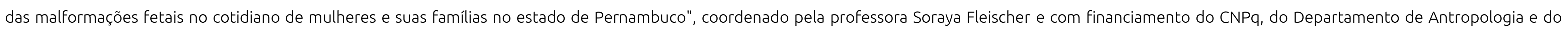

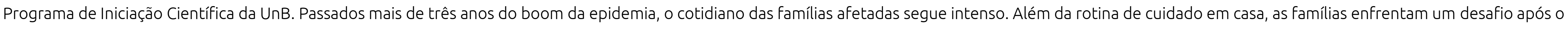

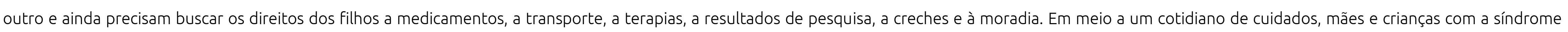
lutam também para não caírem no esquecimento.

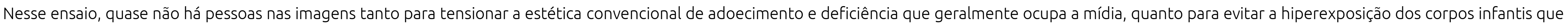

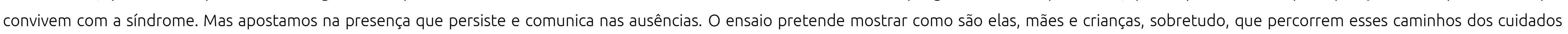
cotidianos.

1 Graduanda em Antropologia pela Universidade de Braślia. Contato: anaclaudiadecamargo@hotmail.com

Jornalista na Empresa Brasil de Comunicação (EBC) e especialista em Saúde Coletiva pela Fiocruz Brasília. Contato: flaviadelima@gmail.com

Doutora em Antropologia Social pela Universidade Federal do Rio Grande do Sul e Professora Associada do Departamento de Antropologia na Universidade de Brasilia. Contatos: soraya@unb.br e hteps://microhistorias.wixisite.com/microhistorias 


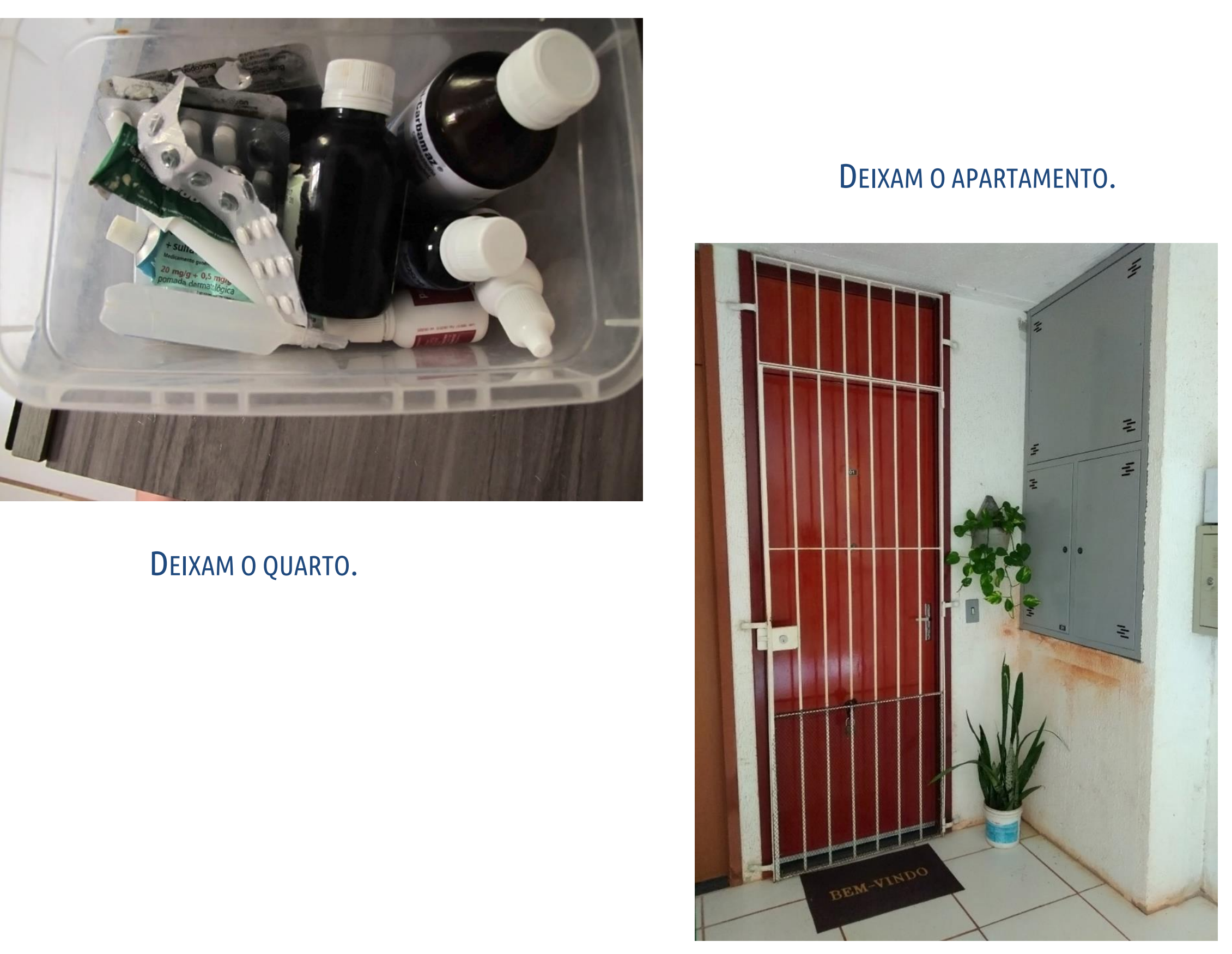

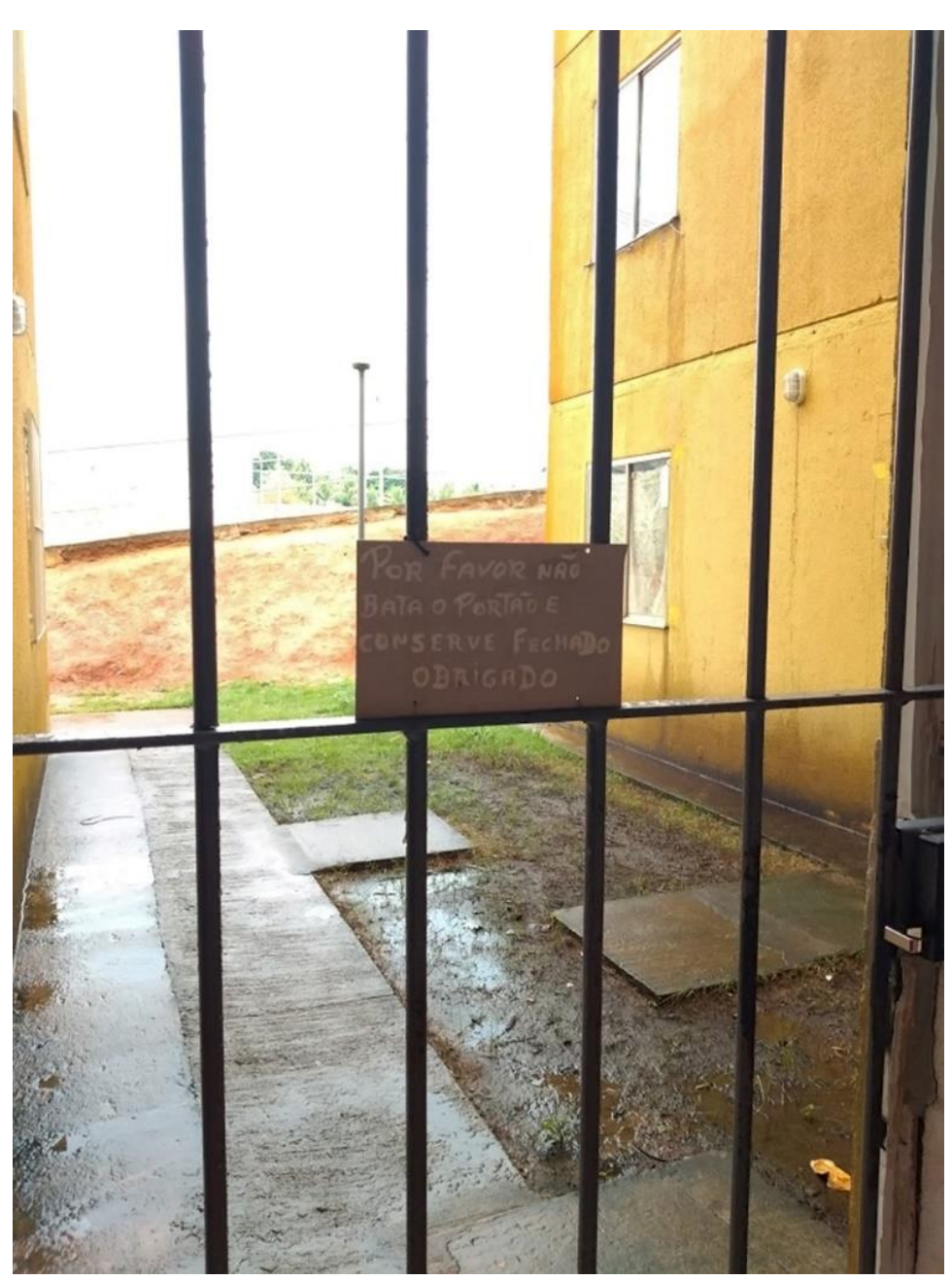

DeIXAM O PRÉdIO.
DEIXAM O CONDOMÍNIO.

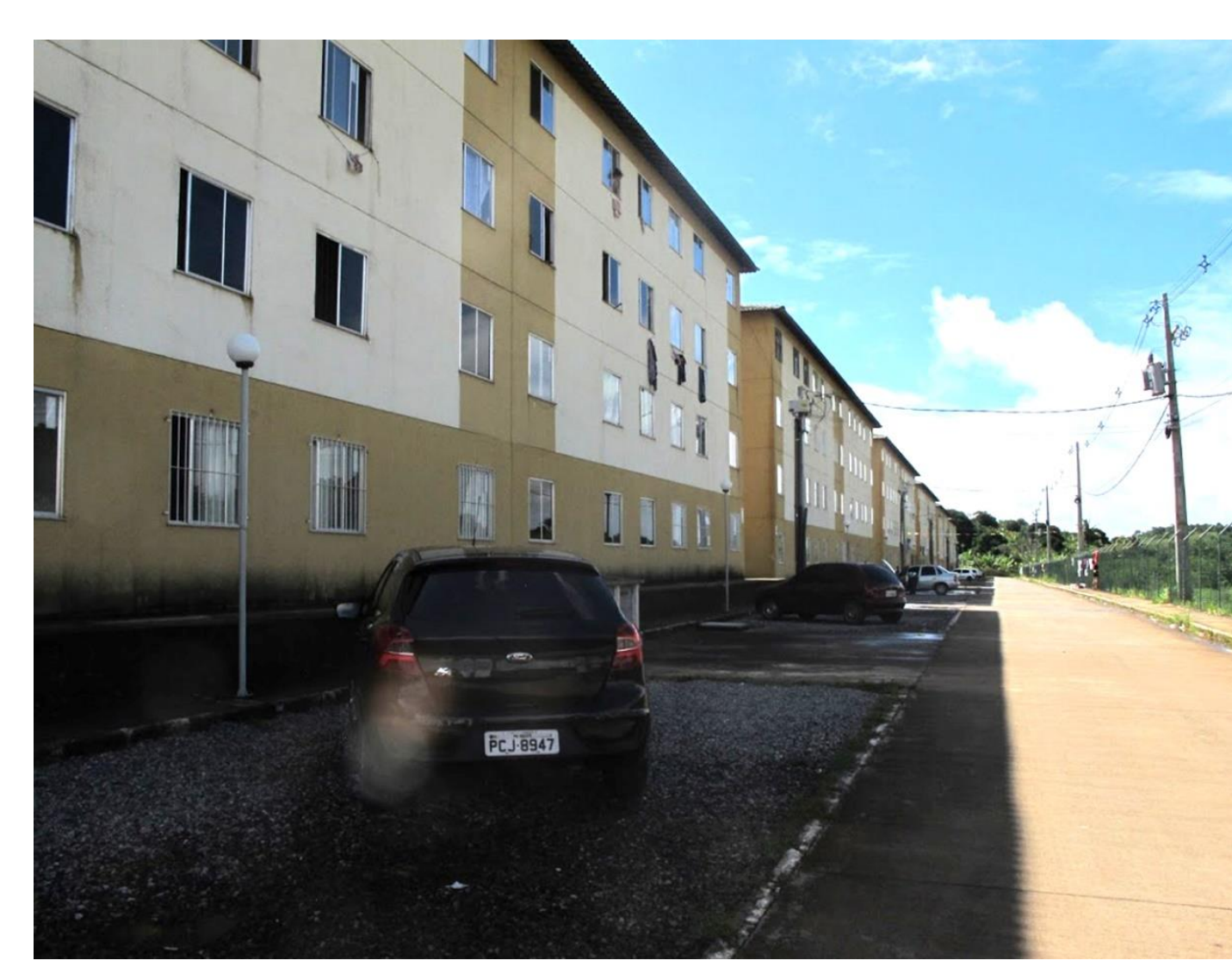



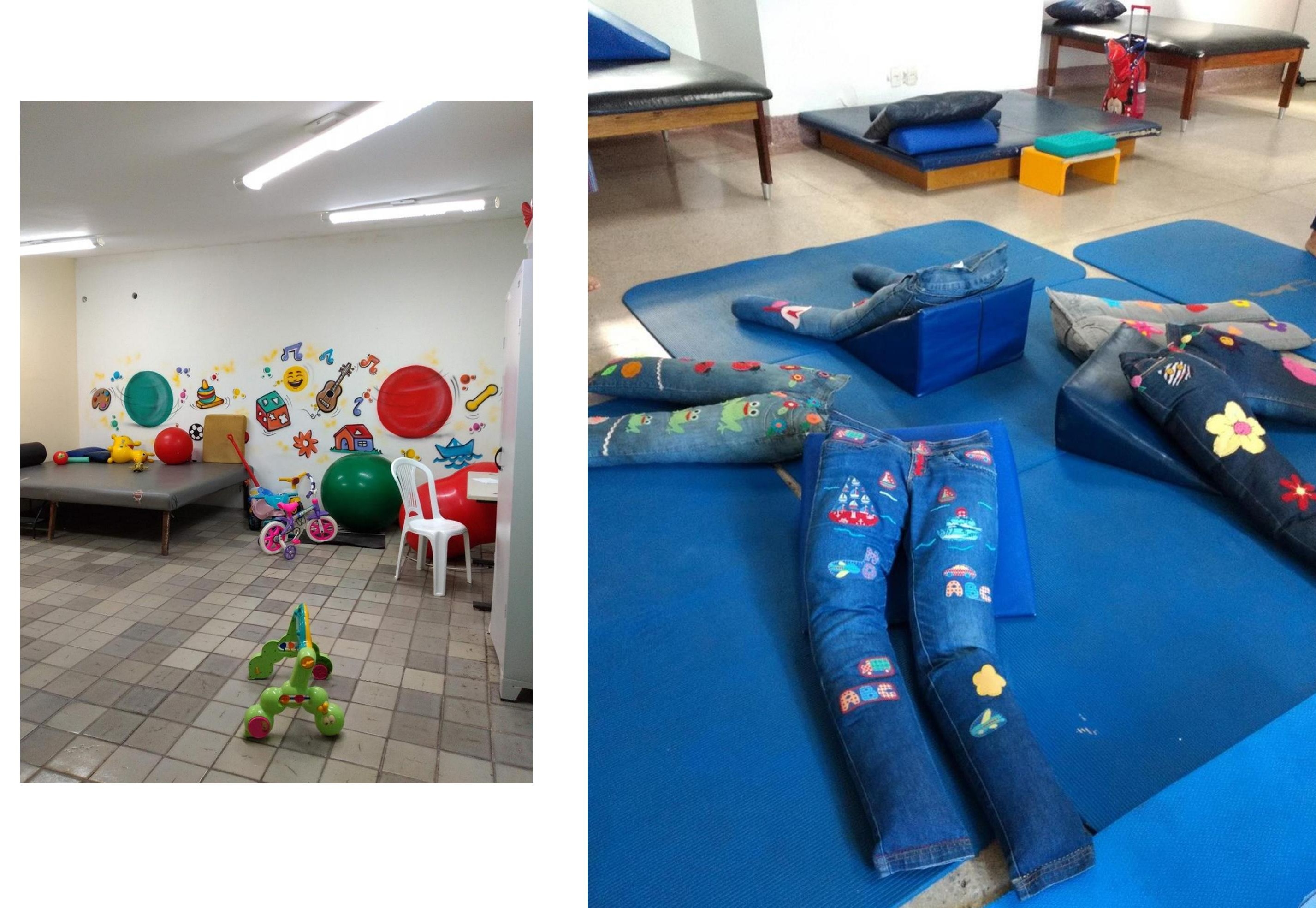
TERÇA-FEIRA:
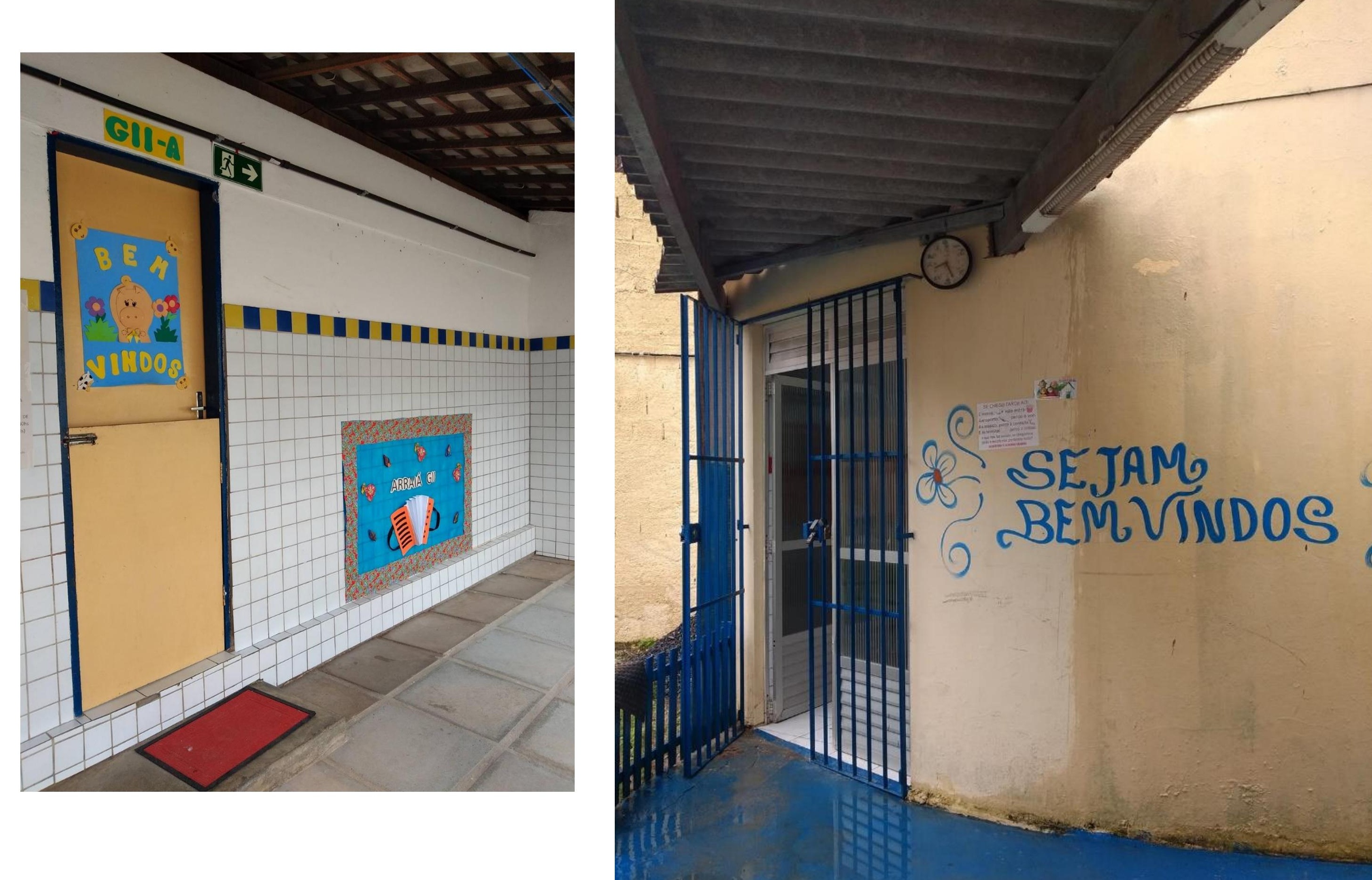
QUARTA-FEIRA DE MANHÃ: CONSULTA COM NEUROLOGISTA
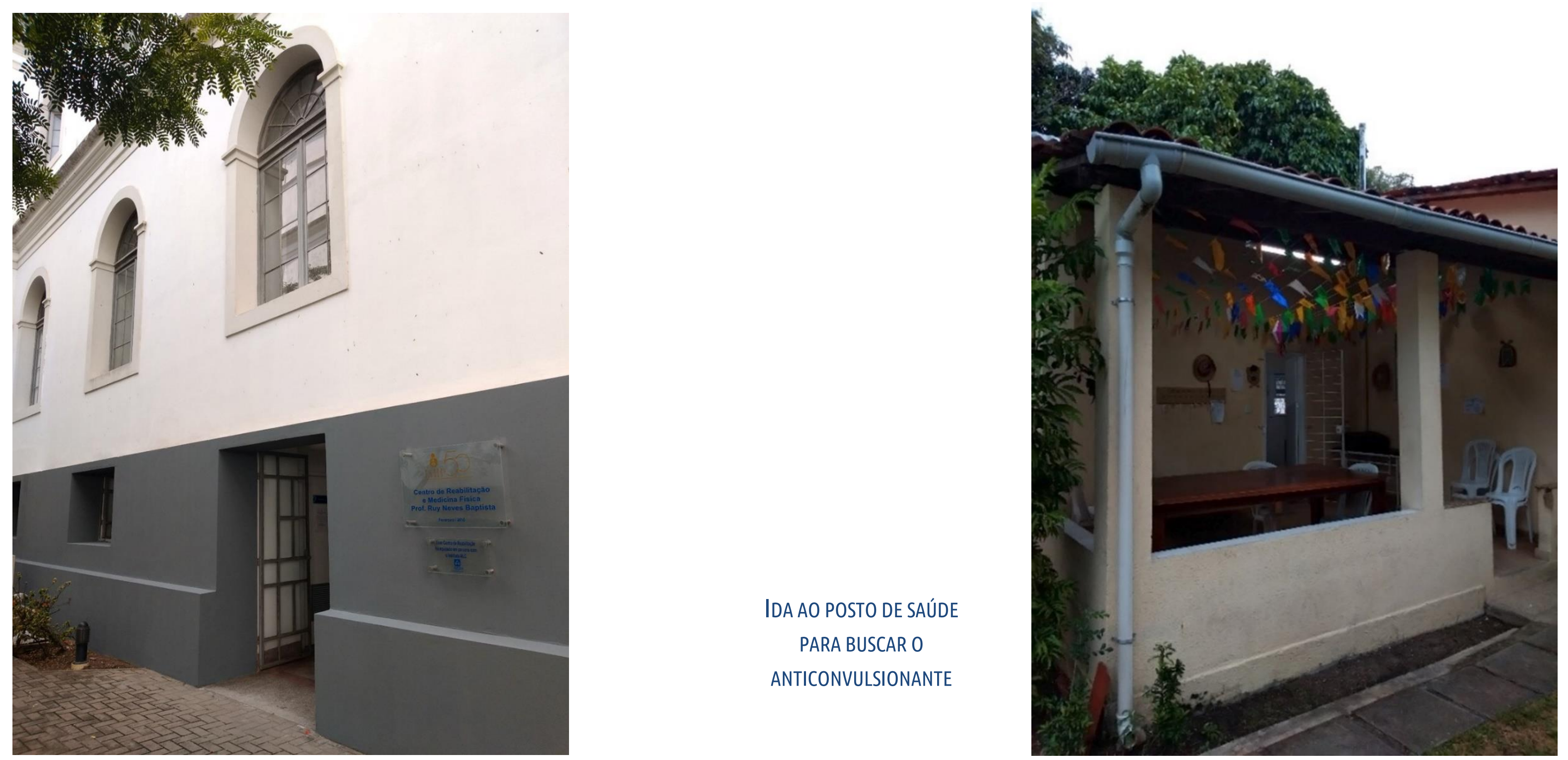

IDA AO POSTO DE SAÚDE

PARA BUSCAR 0

ANTICONVULSIONANTE 
QUARTA-FEIRA DE

TARDE:

CReChe

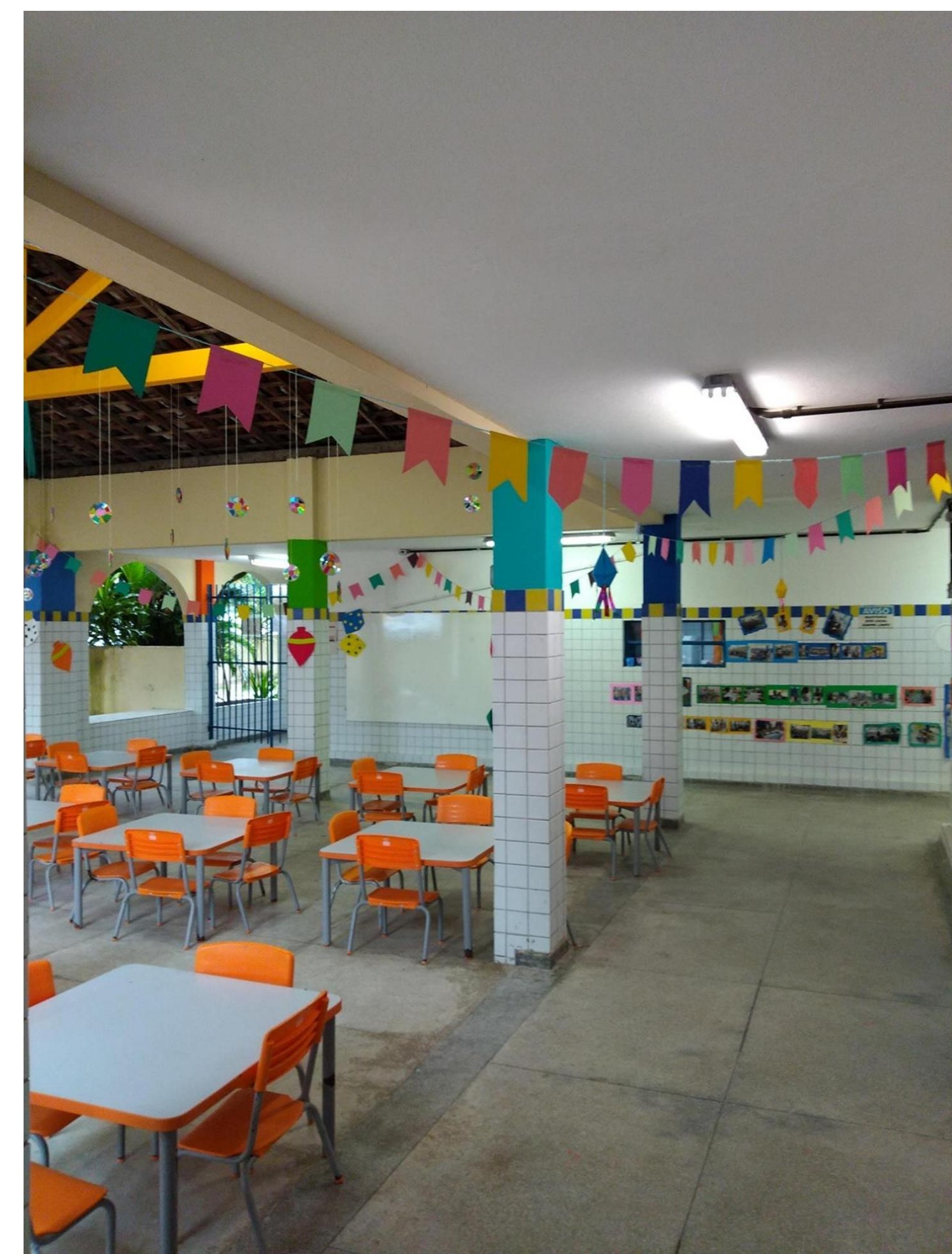




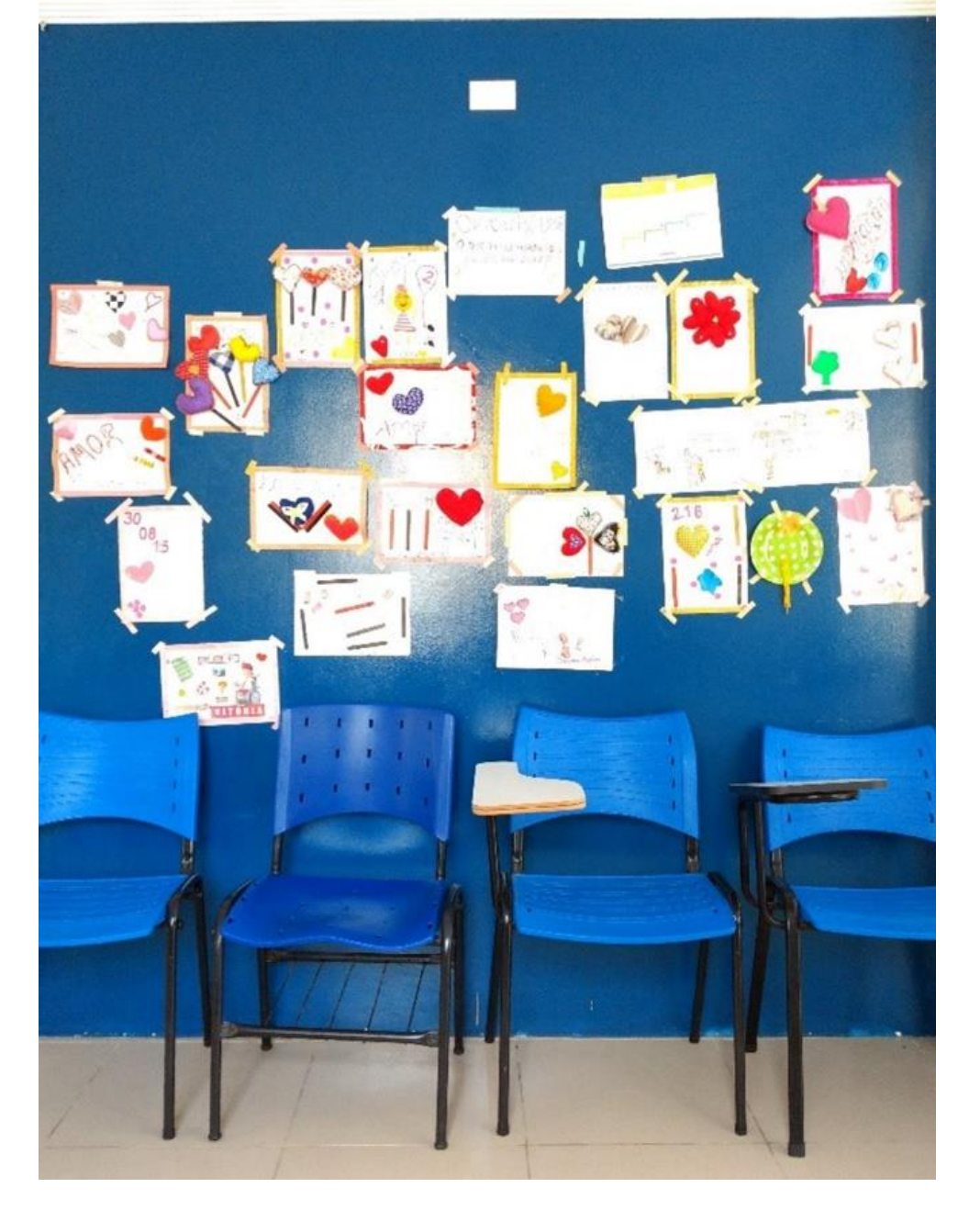

QUINTA-FEIRA

DE MANHÃ:

REUNIÃO DO GRUPO

DE MÃES

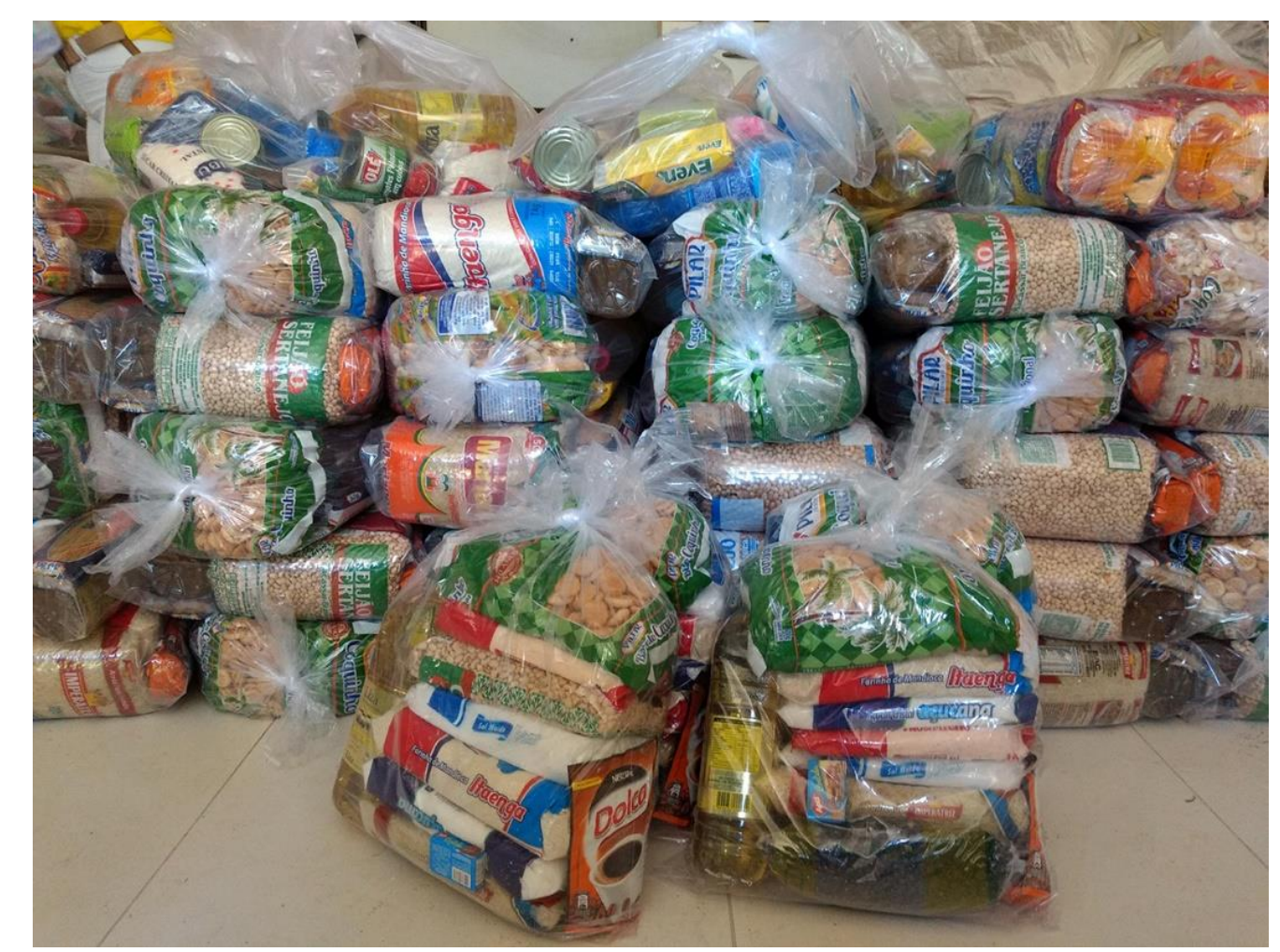

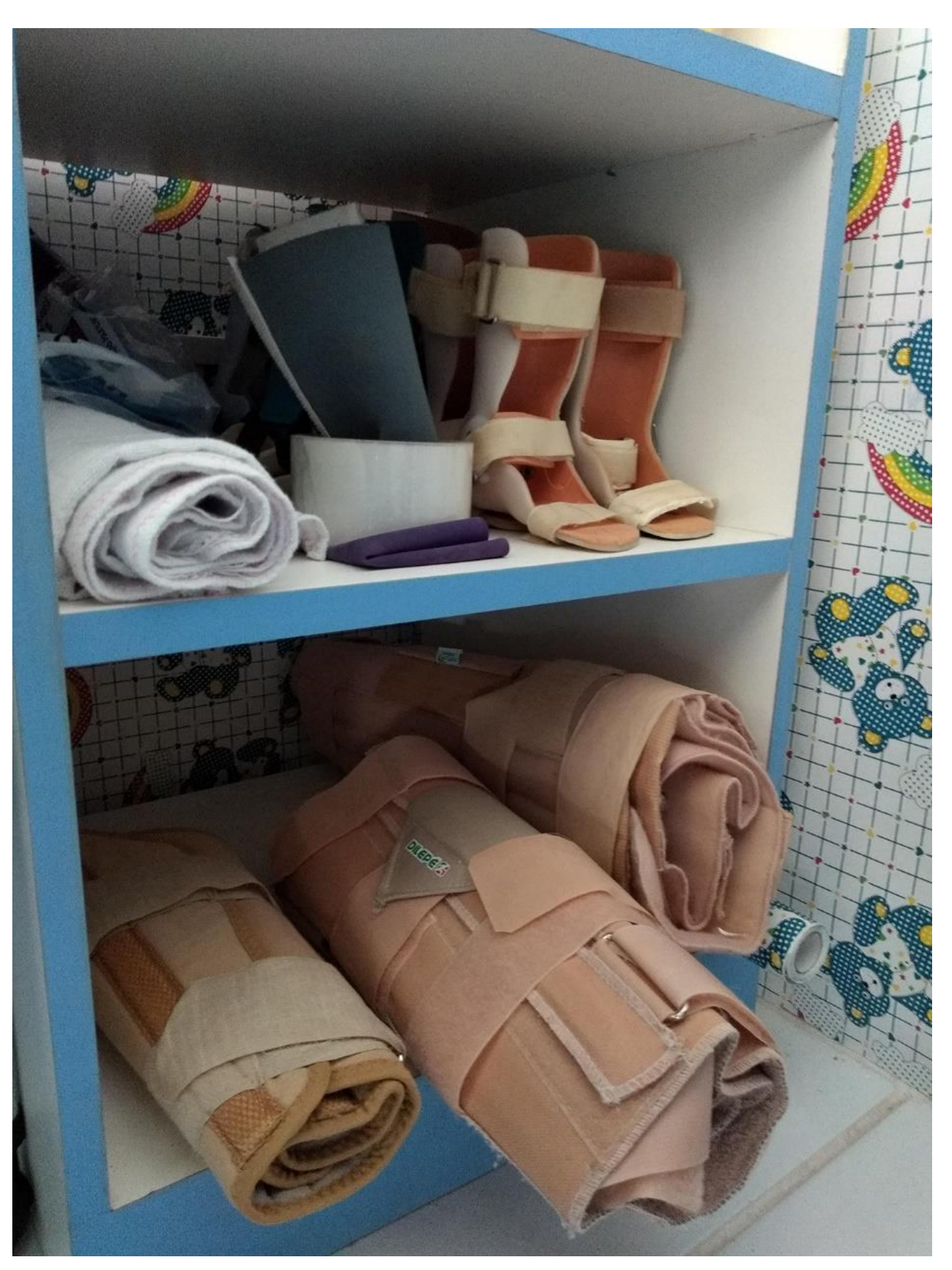




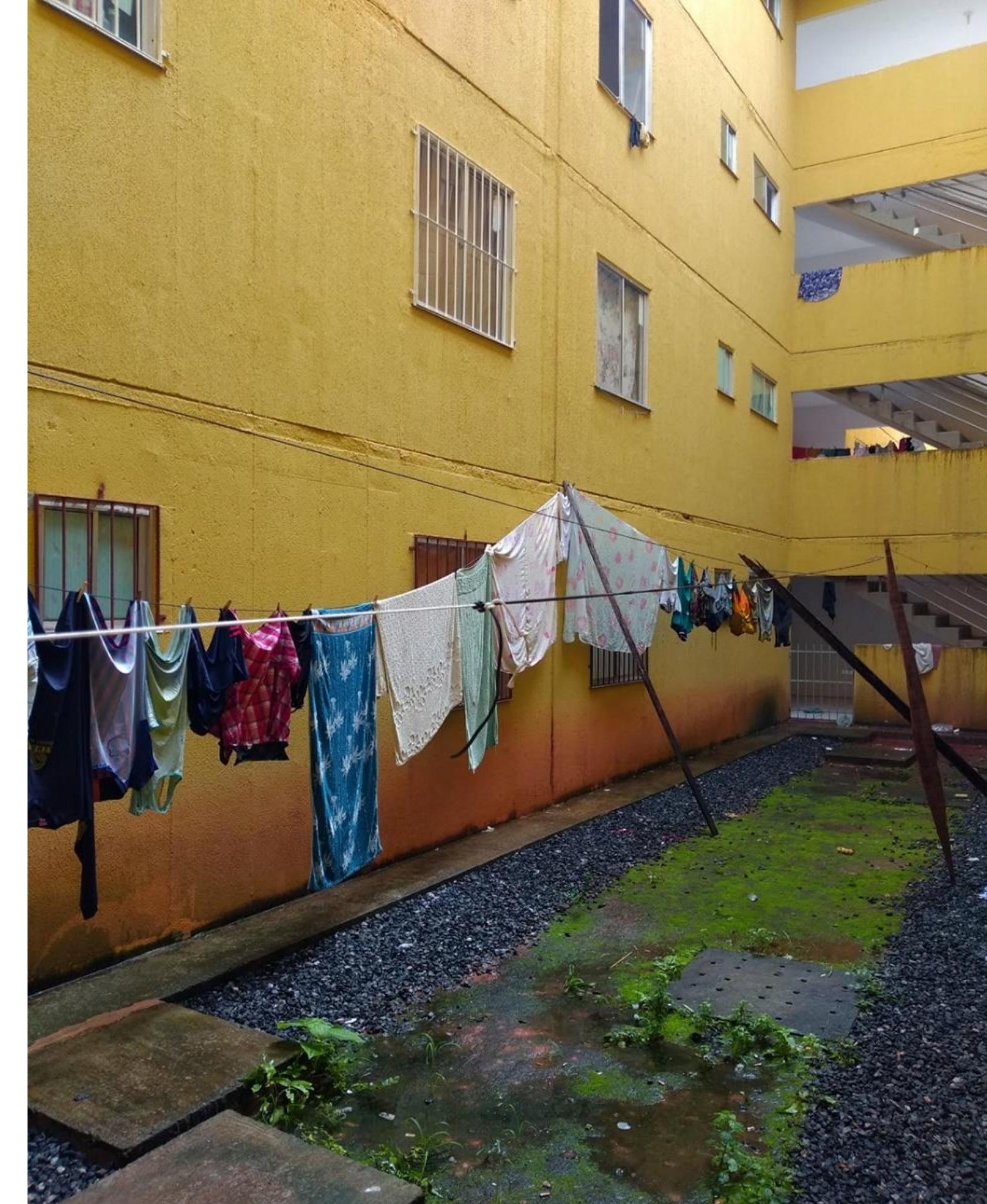




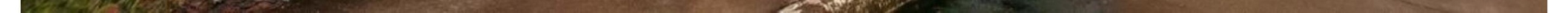


Junho de 2019, Recife, Olinda, Jaboatão dos Guararapes/Pernambuco. Fotos de Ana Claudia Camargo e Soraya Fleischer Montagem, edição e tratamento das imagens por Flavia Lima, Ana Claudia Camargo e Soraya Fleischer

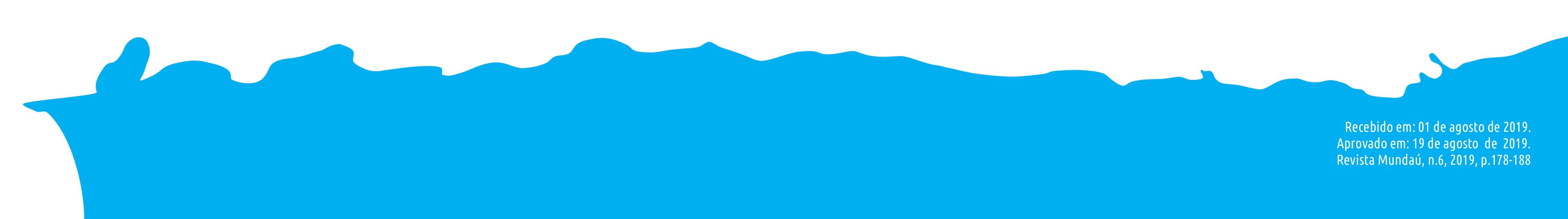

